\title{
The effects of psychoeducational family intervention on coping strategies of relatives of patients with bipolar I disorder: results from a controlled, real-world, multicentric study
}

This article was published in the following Dove Press journal:

Neuropsychiatric Disease and Treatment

\begin{abstract}
Gaia Sampogna,' Mario Luciano,' Valeria Del Vecchio,' Claudio Malangone, ${ }^{1,2}$ Corrado De Rosa,' Vincenzo Giallonardo,' Giuseppina Borriello,' Benedetta Pocai,' Micaela Savorani,' Luca Steardo Jr,' Debora Lampis, ${ }^{3}$ Franco Veltro, ${ }^{4}$ Francesco Bartoli, ${ }^{5}$ Francesco Bardicchia, ${ }^{6}$ Anna Maria Moroni, ${ }^{7}$ Giusy Ciampini, ${ }^{8}$ Emanuele Orlandi, ${ }^{9}$ Silvia Ferrari, ${ }^{10}$ Silvia Biondi, " Sonia lapichino, ${ }^{11,12}$ Enrico Pompili, ${ }^{13}$ Massimiliano Piselli, ${ }^{14}$ Alfonso Tortorella, ${ }^{15}$ Giuseppe Carrà, ${ }^{5,16}$ Andrea Fiorillo'

'Department of Psychiatry, University of Campania “Luigi Vanvitelli”, Naples, ${ }^{2}$ Mental Health Centre of Ravello, Mental Health Unit, Ravello, ${ }^{3}$ Mental Health Centre of Lanusei, Mental Health Unit, Lanusei, ${ }^{4}$ Mental Health Department of Campobasso, Campobasso, ${ }^{5}$ Department of Medicine and Surgery, University of Milano Bicocca, Monza, 'Mental Health Centre of Grosseto, Mental Health Unit, Grosseto, ${ }^{7}$ Niguarda Hospital, Department of Psychiatry, Milan, ${ }^{8}$ Mental Health Centre of Lanciano, Mental Health Unit, Lanciano, ${ }^{9}$ Mental Health Centre of Sassuolo, Mental Health Unit, Sassuolo, ${ }^{10}$ University of Modena and Reggio Emilia, Department of Psychiatry, Reggio Emilia, "Mental Health Centre of Montecatini, Mental Health Unit, Montecatini, ${ }^{12}$ Auditor Psychiatrist, for the activities of Clinical Risk Management and safety of treatments, Tuscany Region, ${ }^{13}$ Mental Health Centre of Rome, Mental Health Unit, Rome, ${ }^{14}$ Mental Health Centre of Foligno, Mental Health Unit, Foligno, ${ }^{15}$ Department of Medicine, Section of Psychiatry, University of Perugia, Perugia, Italy; ${ }^{16}$ Division of Psychiatry, University College of London, London, UK
\end{abstract}

Correspondence: Gaia Sampogna Department of Psychiatry, University of Campania “Luigi Vanvitelli”, Largo Madonna delle Grazie, 80138 Naples, Italy Tel/fax +39 08I 566653 I

Email gaia.sampogna@unicampania.it
Background: Psychoeducational family intervention (PFI) has been proven to be effective in improving the levels of family burden and patients' personal functioning in schizophrenia and bipolar disorders (BDs). Less is known about the impact of PFI on relatives' coping strategies in $\mathrm{BD}$.

Methods: A multicenter, controlled, outpatient trial funded by the Italian Ministry of Health and coordinated by the Department of Psychiatry of the University of Campania "Luigi Vanvitelli" has been conducted in patients with bipolar I disorder (BD-I) and their key relatives consecutively recruited in 11 randomly selected Italian community mental health centers. We aim to test the hypothesis that PFI improves problem-oriented coping strategies in relatives of BD-I patients compared to the Treatment As Usual (TAU) group.

Results: The final sample was constituted of 123 patients and 139 relatives. At baseline assessment (T0), the vast majority of relatives already adopted problem-oriented coping strategies more frequently than the emotion-focused ones. At the end of the intervention, relatives receiving PFI reported a higher endorsement of adaptive coping strategies, such as "maintenance of social interests" (odds ratio $[\mathrm{OR}]=0.309, \mathrm{CI}=0.04-0.57 ; p=0.023$ ), "positive communication with the patient" $(\mathrm{OR}=0.295, \mathrm{CI}=0.13-0.46 ; p=0.001)$, and "searching for information" $(\mathrm{OR}=0.443$, $\mathrm{CI}=0.12-0.76$; $p=0.007$ ), compared to TAU relatives, after controlling for several confounders. As regards the emotion-focused coping strategies, relatives receiving the experimental intervention less frequently reported to adopt "resignation" $(\mathrm{OR}=-0.380, \mathrm{CI}=-0.68$ to $-0.08 ; p=0.014)$ and "coercion" ( $\mathrm{OR}=-0.268, \mathrm{CI}=-0.46$ to $-0.08 ; p=0.006)$ strategies, compared to TAU relatives. Conclusion: PFI is effective in improving the adaptive coping strategies of relatives of BD-I patients, but further studies are needed for evaluating the long-term benefits of this intervention. Keywords: coping strategies, family burden, psychoeducation family intervention, bipolar disorder, social functioning

\section{Introduction}

Following the seminal work with families of people with bipolar disorders (BDs) by Miklowitz et $\mathrm{al}^{1}$ and Miklowitz and Goldstein, ${ }^{2}$ it became clear that relatives have an extreme need to be supported in managing their family member's illness and to learn adaptive strategies to cope with the situation. ${ }^{3}$ In particular, Miklowitz and Chung found that relatives - following a mood episode - are usually very anxious about the risk of a new mood episode; sometimes, they decide to stop working or change the daily routine in order to take care of their ill relative. ${ }^{4}$ These caregivers seem to have 
an emotional overinvolvement similar to that of family members of patients with schizophrenia, ${ }^{5,6}$ reporting high levels of subjective and objective burden, restrictions in social life, a high risk to develop depressive or anxiety symptoms, financial and working difficulties, general global health problems, and a reduced quality of life. ${ }^{7-12}$ Moreover, caregivers often report feelings of powerlessness, hopelessness, and inability to change the situation. ${ }^{13,14}$

Relatives develop different strategies to deal with patients' symptoms and behaviors, which are defined "coping strategies". Lazarus and Folkman ${ }^{15}$ identified two patterns of relatives' coping strategies: problem- and emotion-focused strategies. The former refers to the adaptive efforts to impact on stressful situations by using problem-solving and other cognitive personal resources (such as seeking for information about the disorder, using positive communication skills with the patient, finding support from friends, engaging in leisure activities). ${ }^{16}$ The latter can be defined as the emotional reactions to patient's behaviors or symptoms and include avoidance, collusion, resignation, and coercion. ${ }^{14}$

A significant association between relatives' coping strategies and the long-term outcome of BD patients has been found. In particular, when relatives adopt effective coping strategies to deal with patients' disturbing behaviors, patients can feel less stigmatized and stressed and report a reduced rate of relapses and hospitalization. ${ }^{17}$ Moreover, coping strategies are closely linked with the level of family functioning, emotional involvement, and severity of patients' clinical status; ${ }^{13}$ and the adoption of adaptive coping strategies can reduce the levels of family burden. ${ }^{14,18,19}$

According to several studies ${ }^{20,21}$ and international guidelines, ${ }^{22,23}$ the optimal management of BD patients should include the provision of psychoeducational family interventions (PFIs), in order to improve long-term clinical and functional outcomes of patients and their relatives. ${ }^{14,17-19,24}$

Jönsson et $\mathrm{al}^{14}$ showed that relatives of BD patients receiving an educational intervention improve their coping strategies, and these results were confirmed in two other studies also. ${ }^{25,26}$ However, these findings came from clinical trials with a small sample size and were not implemented in real-world settings. Moreover, the PFI, according to the Falloon model, ${ }^{27}$ has been proven to be effective in improving adaptive coping strategies (such as positive communication and seeking for information) in relatives of patients with schizophrenia, ${ }^{28}$ but it has never been tested in relatives of BD patients.

Within a multicenter study funded by the Italian Ministry of Health and coordinated by the University of Campania "Luigi Vanvitelli" on the evaluation of the efficacy of PFI for families of bipolar I disorder (BD-I) patients in the real-word setting, we aim to test the hypothesis that PFI is effective in improving problem-oriented coping strategies in a sample of relatives of BD-I patients compared to the Treatment As Usual (TAU) group.

\section{Methods}

This study is based on the secondary analyses of data collected in a multicenter, controlled, outpatient trial conducted in BD-I patients and their key relatives consecutively recruited in 11 randomly selected Italian community mental health centers. Eleven mental health centers were selected by using a randomization procedure performed by a statistician from the Coordinating Center. ${ }^{29,30}$

\section{Patients' inclusion and exclusion criteria}

Inclusion criteria for patients were the following: 1) age between 18 and 65 years; 2) diagnosis of BD-I according to the Diagnostic and Statistical Manual of Mental DisordersFourth Edition (Text Revision) criteria; ${ }^{31} 3$ ) on the caseload of the local mental health center for at least 6 months, with a minimum of one contact per month in the last 12 months; 4) at least one affective episode in the past 3 years; 5) living with at least one relative; and 6) providing informed consent to participate in the study and to involve their relatives.

All patients who agreed to participate were asked for their permission to contact and involve their key relative(s). For each patient, one or more key relatives could be recruited. Key relatives were defined as those spending the highest number of hours in contact with the patient during the last year. ${ }^{32}$

Relatives' inclusion criteria were: 1) age between 18 and 70 years, and 2) absence of any disabling physical or mental disorder.

\section{Recruitment}

According to the study's protocol, each participating center was expected to recruit at least 16 families of $\mathrm{BD}$ patients.

Patients and their key relatives who agreed to participate in the study were consecutively allocated to the experimental group (up to eight families per center), or to a waiting list, receiving the intervention at the end of the study (TAU). ${ }^{29,30}$ A consecutive recruitment procedure was adopted for reducing the contamination between subjects in the study centers.

\section{Description of the experimental intervention}

The experimental intervention is based on the PFI developed by Ian Falloon in 1985 for patients affected by schizophrenia and their relatives. ${ }^{27}$ 
The intervention consists of three or four informative sessions, at least four communication skills sessions, and two or three problem-solving sessions. Sessions take place three times a month for a period ranging from 4 to 6 months (about 18 sessions in total). Each session lasts about 90 minutes. Site and frequency of sessions are adapted to families' needs and mental health professionals' duties and workloads.

The Falloon intervention has been adapted to BD-I by our research group with the following methodology: 1) analysis of scientific literature; 2) evaluation of available handbooks and manuals on psychoeducational approaches for BD-I, ${ }^{33-37}$ and 3 ) focus groups with research researchers and clinical experts and with users and carers, in order to identify the most relevant components to be included in the intervention.

The intervention was discontinued if the following occurred: 1) patients or relatives were unable to attend more than five psychoeducational sessions; or 2) patients were hospitalized or had any affective relapse during the intervention; or 3) patients or relatives withdrew their consent. In both groups, patients continued to receive the treatment usually provided in their center.

\section{Outcome measure}

Herein, we address a new research question on the efficacy of the PFI - according to the Falloon mode ${ }^{27}$ - in improving relatives' coping strategies.

The main outcome measure was the score in the Family Coping Questionnaire ${ }^{38}$ (FCQ). The FCQ is a selfadministered questionnaire consisting of 34 items, which has shown a good reliability and external validity. Each item is rated on a 4-level scale, from 1 (never) to 4 (always). The items can be grouped into the following 11 subscales: seeking for information on patient's illness (two items, Cronbach's alpha value $=0.66$, eg, "I tried to ask for guidance on how to behave toward S"); positive communication toward the patient (six items, Cronbach's alpha value $=0.55$, eg, "Whenever S appeared nervous or anxious, I tried to have him/her sit down and tell me what was wrong, and I tried to be reassuring"); relatives' maintenance of social interests (six items, Cronbach's alpha value $=0.77$, eg, "I had time to think of my own needs or interests"); patient's involvement in social activities (three items, Cronbach's alpha value $=0.49$, eg, "I tried to get $\mathrm{S}$ interested in something that might prove pleasant for him/her"); talking with friends about the patient's condition (one item, "I tried to discuss problems related to $S$ 's situation with my friends"), coercion (five items, Cronbach's alpha value $=0.52$, eg, "When he/she spoke nonsensically, I shouted to him/her to cut the nonsense"), avoidance (two items, Cronbach's alpha value $=0.66$, eg, "I avoided staying alone in S's company"), resignation (three items, Cronbach's alpha value $=0.69$, eg, "I felt that I had no energy left to respond and that I was just waiting for events to happen"); use of alcohol and drugs (one item, "I had to drink or take drugs to forget about S's situation"); collusion (four items, Cronbach's alpha value $=0.60$, eg, "When S said something strange, I agreed with him/her"); and search for spiritual help (one item, "I have prayed or asked for spiritual help because of S's situation"). A higher score is indicative of a stronger endorsement of each coping strategy. The FCQ has been widely used for the assessment of coping strategies among relatives of people with severe mental disorders, such as schizophrenia, ${ }^{38}$ and recently in families of people with eating disorders..$^{39,40}$

\section{Assessment tools}

Patients' clinical status was assessed with the 24-items Brief Psychiatric Rating Scale (BPRS);4 for the purposes of this study, we used the BPRS depressive-anxiety and manic/ hostility subscales.

Patients' social functioning was assessed by the Disability Assessment Schedule, ${ }^{42}$ with higher scores indicating a worse social functioning.

Pharmacologic treatment was considered adequate if at least one mood stabilizer or one antipsychotic drug was prescribed to patients, according to the National Institute for Health and Care Excellence guidelines for the treatment of BD. ${ }^{22}$ Pharmacologic treatment was maintained stable as much as possible in the two groups over the intervention period.

This trial was conceived as a "real-world" study, and there was no possibility to include another active intervention as a comparator besides TAU. According to the study protocol, a waiting list was added in order to minimize the burden for mental health professionals and to guarantee that all relatives and patients would receive the intervention. ${ }^{43-46}$

Patients' clinical and sociodemographic characteristics, as well as relatives' sociodemographic characteristics at the baseline were recorded by ad hoc schedules.

In both groups, patients continued to receive the treatment usually provided in their center.

Patients and relatives were assessed prior to the beginning of the intervention (T0 assessment) and at the end of the intervention ( $\mathrm{T} 1$ assessment).

\section{Ethical approval}

The study was conducted in accordance with the ethical principles of the Declaration of Helsinki. All patients and relatives received detailed information on the study and 
provided written informed consent. The protocol was submitted to and approved by the Ethical Committee of the University of Campania "Luigi Vanvitelli".

\section{Statistical analyses}

Per-protocol analysis - including only those patients who completed the treatment originally allocated to - was implemented in order to evaluate the effects of treatments in the real-world setting. Making an imputation of the missing values would be out of interest of a real-world study.

Frequency counts and descriptive analyses were performed, as appropriate. Baseline differences in socio-demographic and clinical characteristics were tested using $\chi^{2}$ or Student's $t$-test, as appropriate. In each group, the impact of the experimental intervention and of TAU on relatives' coping strategies was explored by Student's $t$-test for paired samples. Moreover, in order to reduce type 1 error, bootstrap calculation with 1,000 bootstrap replications was implemented and $95 \%$ CI values of bootstrap were reported.

Correlations between coping strategies and relatives' sociodemographic characteristics, as well as between coping strategies and patients' clinical characteristics were explored using the Spearman correlation.

In order to test the efficacy of the experimental intervention on coping strategies, linear regression models were implemented, using the mean score of the FCQ subscales as outcome measures. In particular, the mean score of each FCQ subscale (eg, FCQ - collusion) was used as a continuous variable, and having received or not the experimental intervention was entered as the main predictor (considered as binary variable "Yes vs No"). Each regression model was controlled for patients' clinical and sociodemographic variables (ie, patient's age, gender, years of school, duration of illness, mean scores of BPRS subscales at baseline, Disability Assessment Schedule global score at baseline) and relatives' sociodemographic characteristics (ie, age, gender, type of relationship with the patient, years of cohabiting with the patient, daily hours spent in contact with the patient, being part of the same nuclear family) identified from the relevant literature in the field. ${ }^{16}$ Data analysis was performed using SPSS statistical software, version 18.0; ${ }^{47}$ a two-tailed alpha level of significance was set at $p<0.05$.

\section{Results}

\section{Recruitment process and attrition rate}

One center out of the 11 involved did not run the intervention after training of mental health professionals. The remaining 10 centers were expected to recruit up to 16 patients with BD-I and their key relatives. Of the
143 contacted families, six refused due to lack of time or current family conflicts. Of the remaining 137 families, 70 were consecutively allocated to the experimental group and 67 to the control group.

In the experimental group, 10 families dropped out during the intervention phases, with a retention rate of $93 \%$ (final study sample of 60 families). In the control group, four families dropped out during the study, with a retention rate of 94\% (final study sample of 63 families).

\section{Final sample}

The final sample consisted of 123 patients and 139 relatives, of whom 60 patients and 72 relatives were allocated to the experimental group and 63 patients and 67 relatives to the control group. Sixty-eight relatives out of 139 (49\%) reported to have children. Also, $45.6 \%$ of them were underage and were not included in the study. Patients' and relatives' sociodemographic characteristics as well as patients' clinical features are reported in Table 1.

\section{Description of coping strategies}

The most frequently adopted coping strategy was positive communication with the patient $(3.1 \pm 0.6)$, followed by

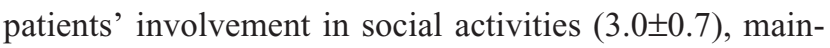
tenance of social interests $(2.6 \pm 0.8)$, and seeking for information (2.3 \pm 1.0$)$. Emotion-focused coping strategies, such

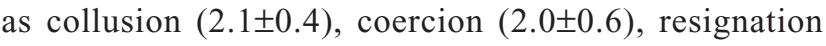

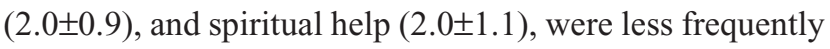
adopted. At baseline, no statistically significant difference in coping strategies was found between the two groups (Table 1).

According to the correlation analyses (Table 2), patients' involvement in social activities was positively associated with a higher educational level of relatives $(\rho=0.183$, $p=0.031$ ) and better psychosocial functioning of patients $(\rho=-0.359, p=0.0001)$. Maintenance of social interests was positively associated with relatives' level of education $(\rho=0.297, p=0.0001)$ and patients' social functioning $(\rho=-0.358, p=0.0001)$, and negatively correlated with patients' depressive symptoms $(\rho=-0.187, p=0.021)$. Seeking for information was associated with worse social functioning of the patients $(\rho=0.479, p=0.0001)$, while talking with friends was associated with a better level of patients' social functioning $(\rho=-0.253, p=0.0001)$.

Collusion was positively associated with relatives' older age $(\rho=0.328, p=0.0001)$, a lower level of education $(\rho=-0.172, p=0.042)$, and more years of cohabiting with the patient ( $\rho=0.171, p=0.045)$. Coercion, avoidance, and resignation were more frequently adopted by relatives of patients 
Table I Sociodemographic and clinical characteristics of the sample

\begin{tabular}{|c|c|c|c|c|c|c|c|c|}
\hline & \multicolumn{4}{|c|}{ Patients group } & \multicolumn{4}{|c|}{ Relatives group } \\
\hline & $\begin{array}{l}\text { Experimental } \\
\text { group }(n=60)\end{array}$ & $\begin{array}{c}\text { Treatment } \\
\text { as usual } \\
\text { group }(n=67)\end{array}$ & $t / \chi^{2}$ & p-value & $\begin{array}{l}\text { Experimental } \\
\text { group }(n=72)\end{array}$ & $\begin{array}{c}\text { Treatment } \\
\text { as usual } \\
\text { group }(n=67)\end{array}$ & $t / \chi^{2}$ & $p$-value \\
\hline Gender, F, \% (n) & $56.7(34)$ & $65 . I(4 I)$ & 0.471 & 0.392 & $56.9(4 I)$ & $59.7(40)$ & 0.044 & 0.430 \\
\hline Age, $M(S D)$ & $50.0(10.3)$ & $48.6(12.2)$ & 0.975 & 0.458 & $50.9(12.9)$ & $52.7(13.8)$ & 0.734 & 0.780 \\
\hline Marital status, married, yes, \% (n) & $66.7(40)$ & $54.0(34)$ & 0.960 & 0.239 & $68.1(49)$ & $70.1(47)$ & 0.196 & 0.652 \\
\hline Level of education, high school, \% (n) & $46.7(28)$ & $41.3(26)$ & 1.969 & 0.121 & $36.9(31)$ & $40.0(28)$ & 1.594 & 0.486 \\
\hline Relationship with the patient, \% (n) & & & NA & & & & 3.612 & 0.194 \\
\hline Parent & - & - & & & $22.5(16)$ & $32.8(22)$ & & \\
\hline Spouse/partner & - & - & & & $54.9(39)$ & $43.3(29)$ & & \\
\hline Son/daughter & - & - & & & $9.9(7)$ & $16.4(11)$ & & \\
\hline Sibling & - & - & & & II.3 (8) & $4.5(3)$ & & \\
\hline Other relative & - & - & & & $\mathrm{I} .4(\mathrm{I})$ & $3.0(2)$ & & \\
\hline Employed, yes, \% (n) & $43.3(26)$ & $31.7(20)$ & 1.050 & 0.327 & $55.7(39)$ & $49.2(31)$ & 1.317 & 0.633 \\
\hline Number of family members, M (SD) & $3.4(1.0)$ & $3.2(1.1)$ & -0.732 & 0.761 & - & - & NA & \\
\hline $\begin{array}{l}\text { Daily hours spent with the patient in the last } \\
2 \text { months, } M(S D)\end{array}$ & - & - & NA & & $6.6(3.4)$ & $6.7(3.4)$ & 1.245 & 0.455 \\
\hline Years of cohabiting with the patient, M (SD) & - & - & NA & & $24.6(12.2)$ & $27.9(\mid I .5)$ & 1.586 & 0.760 \\
\hline Duration of illness, years, $M(S D)$ & I4.I (10.0) & $16.0(6.7)$ & 1.099 & 0.598 & - & - & NA & \\
\hline Months in charge at the MHC, M (SD) & $73.2(69.0)$ & $103.5(75.3)$ & 2.326 & 0.032 & - & - & NA & \\
\hline No. of voluntary admissions lifetime, M (SD) & $2.7(4.1)$ & $3.0(3.4)$ & 0.430 & 0.743 & - & - & NA & \\
\hline No. of involuntary admissions lifetime, M (SD) & $0.7(2.0)$ & $1.5(4.2)$ & 1.345 & 0.299 & - & - & NA & \\
\hline Suicide attempts, yes, \% (n) & $23.7(14)$ & $23.8(15)$ & 0.008 & 0.983 & - & - & NA & \\
\hline BPRS, manic/hostility symptoms, M (SD) & I.3 (0.5) & $1.3(0.5)$ & 0.584 & 0.348 & - & - & NA & \\
\hline BPRS, depression/anxiety symptoms, M (SD) & $2.0(0.7)$ & $2.1(0.8)$ & 0.516 & 0.176 & - & - & NA & \\
\hline DAS global score, M (SD) & $2.9(1.0)$ & $2.8(1.0)$ & 0.425 & 0.371 & - & - & NA & \\
\hline Antipsychotics, yes, \% (n) & $61.7(37)$ & $57.1(36)$ & 0.001 & 0.267 & - & - & NA & \\
\hline Mood stabilizers, yes, \% (n) & $86.7(52)$ & $85.7(54)$ & 0.143 & 0.588 & - & - & NA & \\
\hline Antidepressants, yes, \% (n) & $41.7(25)$ & $34.9(22)$ & 2.049 & $0.74 I$ & - & - & NA & \\
\hline FCQ - positive communication, M (SD) & - & - & NA & & $3.1(0.6)$ & $3.1(0.6)$ & 0.787 & 0.722 \\
\hline $\begin{array}{l}\text { FCQ - patient's involvement in social } \\
\text { activities, } M(S D)\end{array}$ & - & - & NA & & $3.0(0.7)$ & $3.0(0.7)$ & 0.490 & 0.395 \\
\hline $\begin{array}{l}\text { FCQ - relatives' maintenance of social } \\
\text { interests, } M(S D)\end{array}$ & - & - & NA & & $2.7(1.0)$ & $2.5(0.8)$ & 0.074 & 0.210 \\
\hline FCQ - seeking for information, M (SD) & - & - & NA & & $2.4(1.0)$ & $2.3(0.9)$ & 0.771 & 0.349 \\
\hline FCQ - collusion, M (SD) & - & - & NA & & $2.1(0.3)$ & $2.1(0.4)$ & 0.520 & 0.501 \\
\hline FCQ - spiritual help, M (SD) & - & - & NA & & $2.1(1.1)$ & $2.0(1.2)$ & 0.714 & 0.129 \\
\hline $\begin{array}{l}\text { FCQ - talking with friends about patient's } \\
\text { condition, M (SD) }\end{array}$ & - & - & NA & & $2.1(1.0)$ & $1.9(1.0)$ & 0.271 & 0.379 \\
\hline FCQ - resignation, M (SD) & - & - & NA & & $2.0(0.9)$ & $2.0(0.9)$ & 0.783 & 0.901 \\
\hline FCQ - coercion, M (SD) & - & - & NA & & $2.0(0.5)$ & $2.0(0.6)$ & 0.481 & 0.559 \\
\hline FCQ - avoidance, M (SD) & - & - & NA & & I.4 (0.7) & I.3 (0.6) & 0.676 & 0.495 \\
\hline FCQ - use of alcohol and drugs, M (SD) & - & - & NA & & I.I (0.3) & I.2(0.6) & 0.075 & $0.74 I$ \\
\hline
\end{tabular}

Notes: Mean score of each subscale is reported; score ranges from I (never) to 4 (always) with higher score indicating higher endorsement of each strategy. Significant $p$-values have been highlighted in bold characters.

Abbreviations: BPRS, Brief Psychiatric Rating Scale; DAS, Disability Assessment Schedule; FCQ, Family Coping Questionnaire; M, mean score; SD, standard deviation; MHC, mental health center; NA, not applicable.

with higher levels of symptoms of the two BPRS subscales and with worse social functioning (Table 2).

\section{Efficacy of the PFI}

At the end of the intervention, the $t$-test for independent samples along with 95\% CI bootstrap highlighted that relatives in the experimental group endorsed, more frequently, a positive communication strategy compared with those in the TAU group, with a mean difference of 0.35 (95\% CI: 0.47-0.24; $p=0.001$ ). Moreover, relatives receiving the PFI reported a higher endorsement of seeking for information (mean difference: $0.42,95 \%$ CI: $0.66-0.18 ; p=0.001)$, maintenance of social interests (mean difference: $0.25,95 \%$ CI: $0.47-0.05$; $p=0.020$ ), and patient's social involvement (mean difference: $0.20,95 \%$ CI: $0.38-0.04 ; p=0.032$ ), compared with relatives from the control group. As regards the emotion-focused 


\begin{tabular}{|c|c|c|c|c|c|c|c|c|}
\hline & \multicolumn{8}{|c|}{ Relatives' sociodemographic characteristics } \\
\hline & \multicolumn{2}{|c|}{ Age } & \multicolumn{2}{|c|}{$\begin{array}{c}\text { Years of } \\
\text { education }\end{array}$} & \multicolumn{2}{|c|}{$\begin{array}{l}\text { Daily hours spent } \\
\text { with the patient }\end{array}$} & \multicolumn{2}{|c|}{$\begin{array}{l}\text { Years spent with } \\
\text { the patient in the } \\
\text { same household }\end{array}$} \\
\hline & $\rho$ & p-value & $\rho$ & $p$-value & $\rho$ & $p$-value & $\rho$ & $p$-value \\
\hline FCQ - coercion & -0.044 & 0.611 & -0.056 & 0.514 & 0.087 & 0.311 & -0.062 & 0.470 \\
\hline FCQ - collusion & 0.328 & 0.000 & -0.172 & 0.042 & -0.002 & 0.980 & $0.17 \mid$ & 0.045 \\
\hline FCQ - avoidance & -0.054 & 0.530 & 0.028 & 0.746 & 0.029 & 0.650 & -0.046 & 0.589 \\
\hline FCQ - resignation & 0.132 & 0.124 & -0.148 & 0.083 & 0.208 & 0.014 & 0.176 & 0.333 \\
\hline FCQ - spiritual help & 0.173 & 0.043 & -0.265 & 0.002 & 0.196 & 0.021 & 0.183 & 0.031 \\
\hline FCQ - use of alcohol and drugs & 0.001 & 0.992 & 0.070 & 0.416 & -0.021 & 0.808 & -0.062 & 0.466 \\
\hline FCQ - patient's involvement in social activities & -0.135 & 0.116 & 0.183 & 0.031 & 0.107 & 0.208 & 0.021 & 0.804 \\
\hline FCQ - positive communication & -0.107 & 0.212 & 0.114 & 0.183 & 0.040 & 0.640 & -0.059 & 0.493 \\
\hline FCQ - relatives' maintenance of social interests & -0.148 & 0.084 & 0.297 & 0.000 & -0.471 & 0.000 & -0.056 & 0.513 \\
\hline FCQ - seeking for information & 0.021 & 0.805 & 0.004 & 0.959 & 0.048 & 0.572 & 0.028 & 0.747 \\
\hline $\begin{array}{l}\text { FCQ - talking with friends about patient's } \\
\text { condition }\end{array}$ & -0.077 & 0.367 & -0.022 & 0.795 & -0.066 & 0.441 & 0.058 & 0.495 \\
\hline
\end{tabular}

Notes: Mean score of each subscale is reported; score ranges from I (never) to 4 (always), with higher score indicating higher endorsement of each strategy. Significant p-values have been highlighted in bold characters.

Abbreviations: $\rho$, rho coefficient; FCQ, Family Coping Questionnaire.

strategies, relatives from the PFI group reported a significant reduction in collusion (mean difference: $-0.16,95 \%$ CI: -0.06 to $-0.25 ; p=0.001$ ), resignation (mean difference: $-0.41,95 \% \mathrm{CI}:-0.18$ to $-0.63 ; p=0.001)$, avoidance (mean difference: $-0.15,95 \%$ CI: -0.01 to $-0.29 ; p=0.035$ ), and coercion (mean difference: $-0.29,95 \% \mathrm{CI}:-0.17$ to $-0.41 ; p=0.001)$, compared with relatives from the TAU group (Table 3).

When considering $t$-test for paired samples, we found that only positive communication (mean difference: $0.19,95 \%$ CI: $0.07-0.33 ; p=0.006$ ) and seeking for information (mean difference: $0.27,95 \%$ CI: $0.05-0.49 ; p=0.028$ ) strategies significantly improved over time in relatives receiving the experimental intervention. As regards the emotion-focused strategies, only collusion (mean difference: $-0.19,95 \% \mathrm{CI}$ : $0.09-0.29 ; p=0.000$ ), resignation (mean difference: -0.32 , 95\% CI: -0.50 to $-0.13 ; p=0.001$ ), and avoidance (mean difference: $-0.17,95 \%$ CI: -0.27 to $-0.06 ; p=0.004$ ) were reduced over time in relatives receiving the PFI (Table 3 ).

\section{Linear regression models}

Regarding the impact of the intervention on relatives' coping strategies, family members receiving the experimental intervention reported higher score in the "maintenance of social interests" subscale (odds ratio [OR] $=0.309, \mathrm{CI}=0.04-0.57$; $p=0.023$ ), "positive communication" subscale ( $\mathrm{OR}=0.295$, $\mathrm{CI}=0.13-0.46 ; p=0.001)$, and the "searching for information" subscale ( $\mathrm{OR}=0.443, \mathrm{CI}=0.12-0.76 ; p=0.007)$, after controlling for confounders (Table 4). As regards the emotion-focused coping strategies, relatives receiving the experimental intervention reported lower scores in "resignation" $(\mathrm{OR}=-0.380, \mathrm{CI}=-0.68$ to $-0.08 ; p=0.014)$, "coercion" $(\mathrm{OR}=-0.268, \mathrm{CI}=-0.46$ to $-0.08 ; p=0.006)$, and "use of alcohol and drugs" subscales ( $\mathrm{OR}=-0.182, \mathrm{CI}=-0.33$ to -0.04 ; $p=0.014$ ), after controlling for confounders (Table 5).

\section{Discussion}

The main novelty of our findings is related to the evaluation of the efficacy of the PFI according to the Falloon model in improving coping strategies of relatives of patients with BD-I. In fact, the Falloon model has been found to be one of the most effective psychosocial interventions for improving the family burden and coping strategies of relatives of patients with schizophrenia, ${ }^{32,48-51}$ but until now, no data are available on the efficacy of this model in families of people with BD-I. The majority of trials on PFI for BD have shown a positive impact on relapse prevention, symptom reduction, ${ }^{9,37-39}$ and patients' functioning..$^{29}$ Relatives' coping strategies have been less frequently considered as an outcome measure, despite the evidence clearly showing that high levels of family instability and maladaptive coping strategies can have a negative impact on the long-term outcome of the disorder. ${ }^{13}$

The main findings of our study are the following: 1) relatives of patients with BD tend to adopt, more frequently, problem-oriented coping strategies, such as positive communication, patients' involvement in social activities, maintenance of social interest, and seeking for information, than emotion-focused ones such as collusion, coercion, 


\begin{tabular}{|c|c|c|c|c|c|c|c|c|c|c|c|c|c|}
\hline \multicolumn{14}{|c|}{ Patients' sociodemographic characteristics } \\
\hline \multicolumn{2}{|c|}{ Age } & \multicolumn{2}{|c|}{$\begin{array}{c}\text { Years of } \\
\text { education }\end{array}$} & \multicolumn{2}{|c|}{$\begin{array}{c}\text { Months in } \\
\text { charge at the } \\
\text { MHC }\end{array}$} & \multicolumn{2}{|c|}{$\begin{array}{c}\text { Duration of } \\
\text { illness (years) }\end{array}$} & \multicolumn{2}{|c|}{$\begin{array}{c}\text { BPRS } \\
\text { depressive } \\
\text { symptoms }\end{array}$} & \multicolumn{2}{|c|}{$\begin{array}{l}\text { BPRS manic } \\
\text { symptoms }\end{array}$} & \multicolumn{2}{|c|}{$\begin{array}{l}\text { DAS global } \\
\text { score }\end{array}$} \\
\hline$\rho$ & $p$-value & $\rho$ & $p$-value & $\rho$ & $p$-value & $\rho$ & $p$-value & $\rho$ & p-value & $\rho$ & $p$-value & $\rho$ & $p$-value \\
\hline-0.115 & 0.203 & 0.050 & 0.531 & -0.001 & 0.824 & -0.031 & 0.910 & 0.184 & 0.016 & 0.256 & 0.003 & 0.181 & 0.035 \\
\hline-0.122 & 0.084 & 0.141 & 0.181 & -0.153 & 0.280 & -0.131 & 0.230 & 0.014 & 0.708 & -0.030 & 0.775 & 0.136 & 0.609 \\
\hline-0.117 & 0.507 & 0.132 & 0.324 & -0.035 & 0.096 & -0.198 & 0.873 & 0.184 & 0.033 & 0.162 & 0.050 & 0.294 & 0.001 \\
\hline-0.094 & 0.268 & 0.077 & 0.140 & 0.074 & 0.296 & -0.097 & 0.463 & 0.437 & 0.000 & 0.179 & 0.206 & 0.625 & 0.000 \\
\hline-0.092 & 0.357 & -0.067 & 0.002 & 0.115 & 0.549 & 0.047 & 0.536 & 0.170 & 0.115 & 0.016 & 0.794 & 0.180 & 0.012 \\
\hline-0.063 & 0.687 & 0.153 & 0.299 & -0.005 & 0.796 & 0.007 & 0.898 & -0.034 & 0.796 & 0.080 & 0.112 & -0.016 & 0.874 \\
\hline 0.172 & 0.075 & 0.028 & 0.136 & 0.106 & 0.907 & -0.035 & 0.272 & 0.364 & 0.000 & 0.014 & 0.624 & -0.359 & 0.000 \\
\hline-0.043 & 0.891 & -0.001 & 0.799 & 0.234 & 0.912 & -0.009 & 0.023 & 0.186 & 0.056 & -0.035 & 0.779 & 0.150 & 0.177 \\
\hline 0.004 & 0.942 & 0.132 & 0.239 & 0.034 & 0.811 & -0.004 & 0.642 & -0.187 & 0.021 & -0.119 & 0.193 & -0.358 & 0.000 \\
\hline-0.066 & 0.593 & 0.075 & 0.727 & 0.043 & 0.856 & -0.149 & 0.887 & 0.288 & 0.000 & -0.041 & 0.868 & 0.479 & 0.000 \\
\hline-0.033 & 0.811 & -0.028 & 0.460 & 0.012 & 0.545 & -0.059 & 0.758 & 0.139 & 0.167 & 0.083 & 0.278 & -0.253 & 0.000 \\
\hline
\end{tabular}

resignation, and spiritual help;2) relatives' coping strategies are strongly correlated with patients' symptoms severity and psychosocial functioning; and 3) relatives receiving PFI show a significant reduction in the adoption of emotion-focused strategies and an increase in problem-oriented ones.

The primary hypothesis that the experimental intervention is effective in improving adaptive coping strategies was thus confirmed. In particular, family members receiving the experimental intervention reported an improvement in the adoption of problem-oriented coping strategies with a reduction of the emotion-focused ones. This positive and encouraging finding is in line with studies promoted by Ruffolo et a $l^{52}$ and by Jönsson et al, ${ }^{14}$ who documented that the provision of a family psychoeducational intervention is associated with a change in the pattern of coping styles over time and with a reduction of emotion-focused coping strategies in relatives of patients with BD. Also, Perlick et $\mathrm{al}^{25}$ found that, after providing a family-focused treatment, the reduction in the adoption of emotion-focused coping strategies is associated with an improvement in patients' clinical status. Moreover, in our study, the PFI has been conducted in a real-world setting, which further emphasizes the promising role of such an intervention in clinical practice. However, the improvements found should also be interpreted in the light of global improvement in the levels of family burden and patients' personal functioning (as observed in our previous study). ${ }^{29}$

In our sample, the findings that relatives of patients with $\mathrm{BD}$ adopt, more frequently, problem-oriented coping strategies deserve some further explanations. First, in our sample, patients were recruited in a stable phase of their disorder since PFI is better provided during patients' remission in order to increase patients' adherence to treatment sessions. ${ }^{21}$ Such methodological choice may have an impact on the coping strategies adopted since family members may have already developed some resiliency factors (such as adaptive coping strategies) which could benefit from reinforcement by the PFI sessions..$^{53,54}$ In fact, as van der Voort et al ${ }^{10}$ observed, caregivers' difficulties coping with patients' behaviors are associated with a high number of relapses and hospitalizations, and with symptoms' severity. As reported by Goossens et al, ${ }^{13}$ relatives tend to adopt more primitive coping reactions (such as avoidance) and to less frequently seek support from the social network when patients have more severe symptoms. ${ }^{55}$ This is confirmed by our findings that relatives' coping strategies strongly correlate with patients' severity of illness and psychosocial functioning. In particular, relatives adopted, more frequently, emotion-focused coping strategies when patients had high scores of BPRS subscales and worse social functioning. In fact, when patients have continuous symptoms and a progressive worsening in social functioning, relatives can perceive the situation as not amenable to change, and thus may more easily avoid the situation, feel resigned, or not be able to bear the situation any longer. ${ }^{16}$ The episodic pattern of BD can influence the adoption of relatives' coping strategies, since family members can learn from their previous experience what to do and seem to get used to dealing with the situation, with a consequent reduction in the levels of perceived distress. ${ }^{13,56}$ 


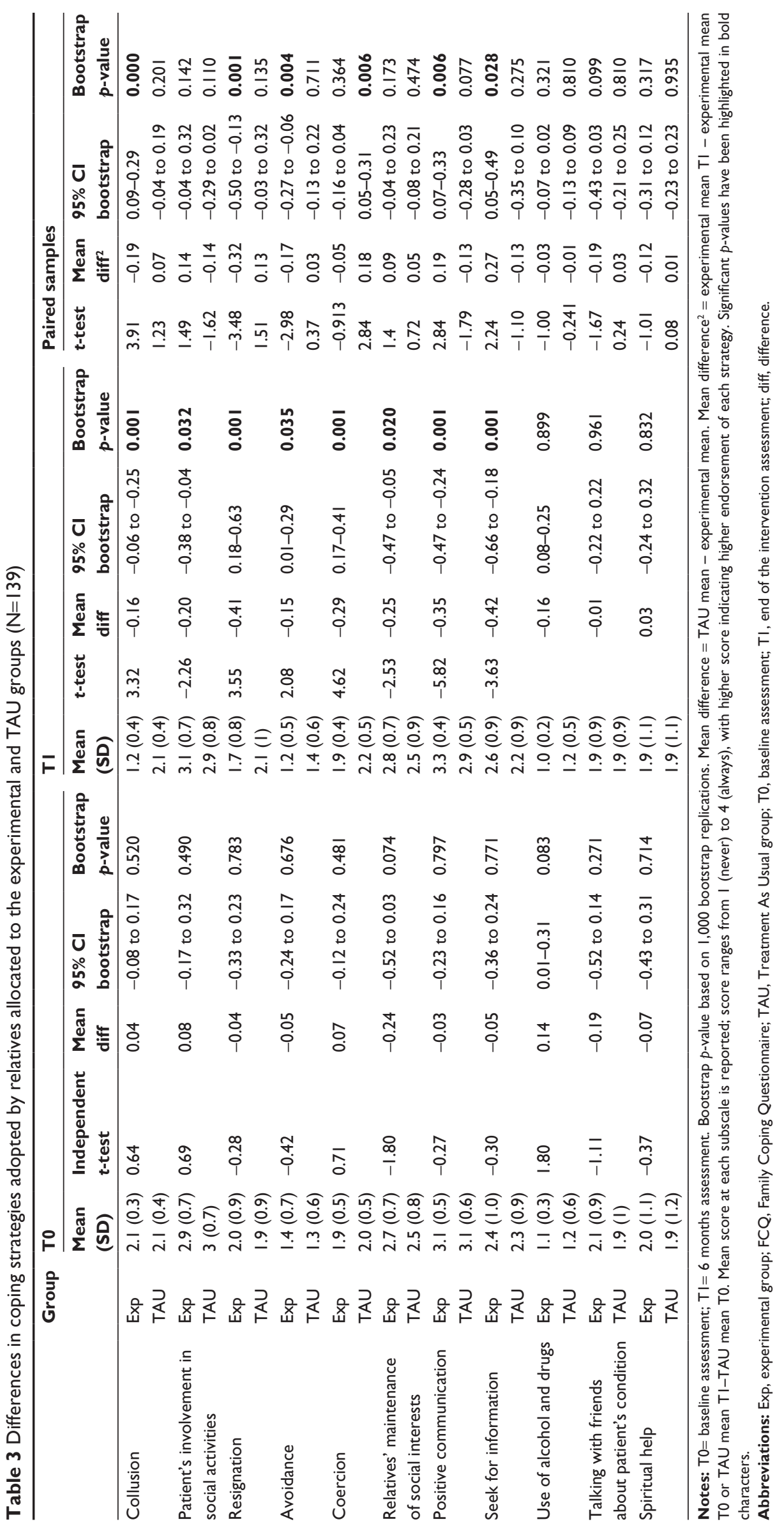




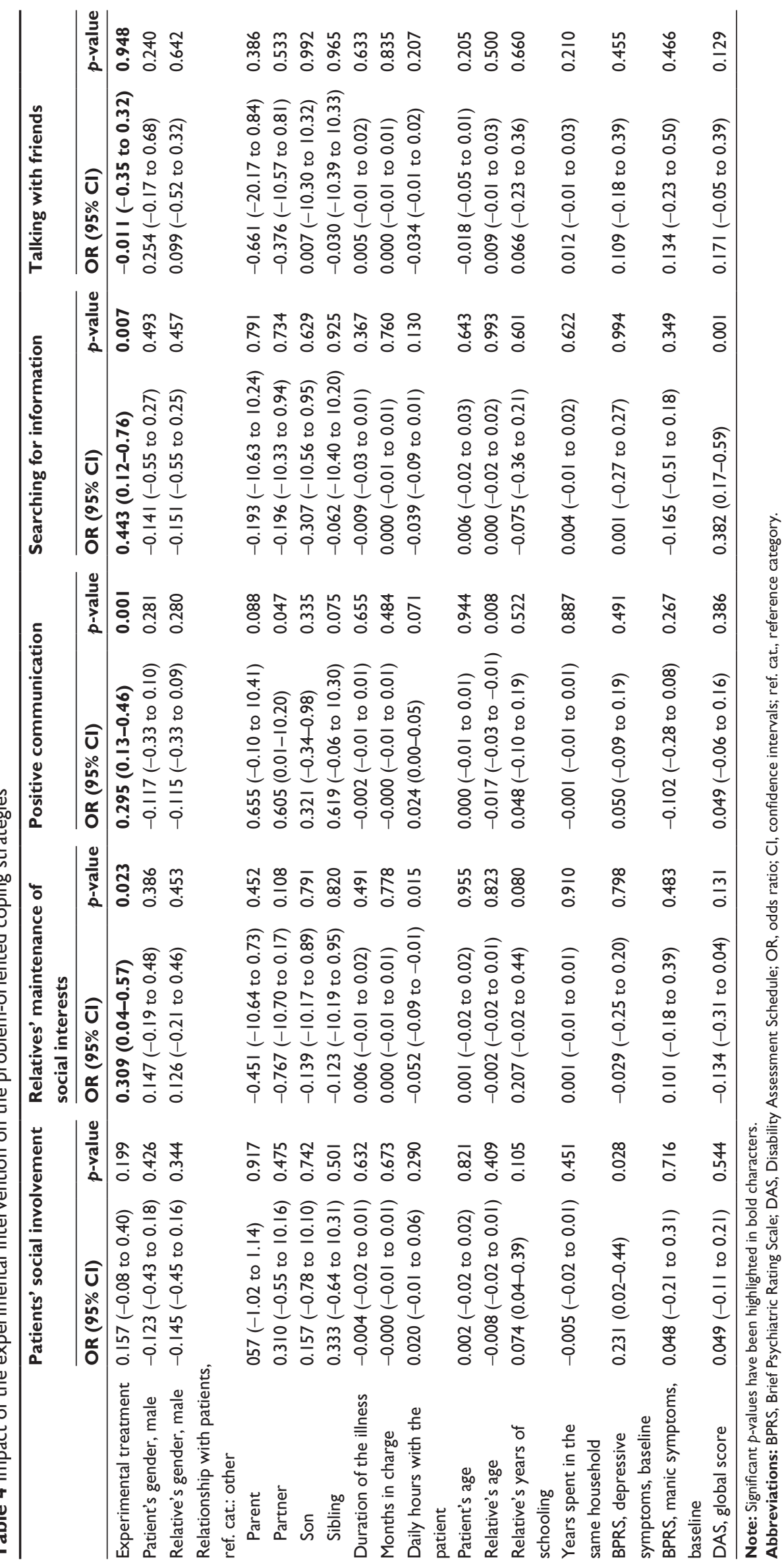


Table 5 Impact of the experimental intervention on the emotion-focused coping strategies

\begin{tabular}{|c|c|c|c|c|c|c|}
\hline & \multicolumn{2}{|l|}{ Collusion } & \multicolumn{2}{|l|}{ Resignation } & \multicolumn{2}{|l|}{ Avoidance } \\
\hline & OR (95\% Cl) & $p$-value & OR (95\% Cl) & $p$-value & OR $(95 \% \mathrm{CI})$ & $p$-value \\
\hline Experimental treatment & $-0.116(-0.25$ to 0.02$)$ & 0.086 & $-0.380(-0.68$ to -0.08$)$ & 0.014 & $-0.185(-0.39$ to 0.01$)$ & 0.070 \\
\hline Patient's gender, male & $0.005(-0.16$ to 0.17$)$ & 0.956 & $-0.336(-0.72$ to 0.04$)$ & 0.083 & $-0.214(-0.47$ to 0.04$)$ & 0.098 \\
\hline Relative's gender, male & $0.048(-0.12$ to 0.21$)$ & 0.566 & $-0.317(-0.69$ to 0.06$)$ & 0.098 & -0.151 ( $(-0.40$ to 0.10$)$ & 0.236 \\
\hline \multicolumn{7}{|l|}{$\begin{array}{l}\text { Relationship with patients, } \\
\text { ref. cat.: other }\end{array}$} \\
\hline Parent & 0.261 ( -0.33 to 0.85$)$ & 0.386 & -0.435 (-10.78 to 0.91$)$ & 0.523 & $0.335(-10.23$ to 0.56$)$ & 0.462 \\
\hline Partner & 0.072 (-0.40 to 0.54$)$ & 0.761 & $-0.112(-10.78$ to 0.95$)$ & 0.835 & $-0.267(-0.98$ to 0.44$)$ & 0.457 \\
\hline Son & $0.112(-0.4 \mid$ to 0.63$)$ & 0.670 & $-0.208(-10.38$ to 0.96$)$ & 0.726 & $-0.727(-10.5 \mid$ to 0.05$)$ & 0.068 \\
\hline Sibling & $0.093(-0.44$ to 0.63$)$ & 0.732 & $-0.574(-10.79$ to 0.64$)$ & 0.352 & $-0.334(-10.14$ to 0.49$)$ & 0.417 \\
\hline Duration of the illness & $-0.005(-0.01$ to 0.00$)$ & 0.269 & $-0.002(-0.02$ to 0.01$)$ & 0.836 & $0.00 \mathrm{I}(-0.0 \mathrm{I}$ to $0.0 \mathrm{I})$ & 0.901 \\
\hline Months in charge & $0.000(-0.00$ to 0.00$)$ & 0.705 & $0.00 \mathrm{I}(-0.0 \mathrm{I}$ to $0.0 \mathrm{I})$ & 0.286 & $0.00 \mathrm{I}(-0.0 \mathrm{I}$ to $0.0 \mathrm{I})$ & 0.247 \\
\hline Daily hours spent with the patient & $-0.003(-0.02$ to 0.02$)$ & 0.806 & $0.021(-0.03$ to 0.07$)$ & 0.374 & $0.002(-0.03$ to 0.03$)$ & 0.910 \\
\hline Patient's age & $0.004(-0.01$ to 0.01$)$ & 0.448 & $-0.008(-0.03$ to 0.01$)$ & 0.515 & $0.001(-0.01$ to 0.01$)$ & 0.895 \\
\hline Relative's age & $0.004(-0.01$ to 0.01$)$ & 0.410 & $-0.003(-0.03$ to 0.02$)$ & 0.772 & $-0.014(-0.03$ to 0.00$)$ & 0.063 \\
\hline Relative's years of schooling & $0.085(-0.03$ to 0.20$)$ & 0.149 & $-0.232(-0.49$ to 0.03$)$ & 0.084 & $0.046(-0.13$ to 0.22$)$ & 0.607 \\
\hline Years spent in the same household & $0.007(-0.00$ to 0.01$)$ & 0.068 & $0.006(-0.01$ to 0.02$)$ & 0.452 & $0.007(-0.00$ to 0.01$)$ & 0.210 \\
\hline BPRS, depressive symptoms, baseline & $-0.027(-0.14$ to 0.09$)$ & 0.632 & $0.137(-0.12$ to 0.39$)$ & 0.290 & $0.036(-0.13$ to 0.21$)$ & 0.679 \\
\hline BPRS, manic symptoms, baseline & 0.031 ( $(-0.11$ to 0.17$)$ & 0.673 & $-0.212(-0.54$ to 0.11$)$ & 0.196 & $0.008(-0.21$ to 0.22$)$ & 0.942 \\
\hline DAS, global score & $0.073(-0.01$ to 0.16$)$ & 0.102 & 0.321 ( 0.12 to 0.52$)$ & 0.002 & $0.090(-0.04$ to 0.22$)$ & 0.178 \\
\hline
\end{tabular}

Notes: Mean score at each subscale is reported; score ranges from I (never) to 4 (always), with higher score indicating higher endorsement of each strategy. Significant p-values have been highlighted in bold characters.

Abbreviations: BPRS, Brief Psychiatric Rating Scale; DAS, Disability Assessment Schedule; OR, odds ratio.

Several sociodemographic characteristics were correlated with relatives' coping strategies. In particular, we found that emotion-focused coping strategies are more frequently adopted by relatives who are older, with a low educational level, and when they have more years of cohabitation with the patient. This finding could be due to the fact that relatives' coping strategies change over time, from adaptive to maladaptive, when the contact or cohabitation with patients increases. Similar results have also been found in relatives of patients with schizophrenia ${ }^{32,57}$ or eating disorders. ${ }^{39,40}$ Interestingly, among problem-oriented coping strategies, only seeking for information was frequently adopted when patients had a worse psychosocial functioning. This probably reflects the relative's need to have appropriate information on how to deal with the patient's disability, and suggests the importance of providing relatives with adequate information about the disorder and what to do in case of patients' disturbing behaviors. ${ }^{52}$

We found that the effect of the intervention was independent from several patients' and relatives' sociodemographic and clinical characteristics, contradicting the hypothesis that psychoeducation is effective only when patients or relatives are younger, and with a short duration of illness. ${ }^{14,58}$

This study has several strengths that are already acknowledged, and some limitations. The first is that relatives' coping strategies have been evaluated through a single self-reported questionnaire. However, the FCQ is a well-known questionnaire with good psychometric properties, which has been used in previous studies involving relatives of patients with severe mental disorders. ${ }^{38-40}$ The second limitation is that patients' symptoms were tested with the BPRS, instead of more specific tools for affective symptoms. However, this choice was due to the fact that the BPRS is a very wellknown, easy-to-use, and reliable instrument that can be adopted in ordinary settings by mental health professionals with a relatively short period of training. The third limitation of the study is the lack of randomization of patients and the relatively small sample size. This was intended as a "real-world" study, and the efficacy of the experimental intervention was tested in the routine care of Italian mental health centers. However, the purposive sampling and the per-protocol analysis adopted may have biased the results, but the sample representativeness has been preserved by the random selection of the participating centers. Moreover, in order to enhance fidelity to real-world settings, perprotocol methodology was adopted, and the imputation of missing data would not have been appropriate for this study. Another possible limitation is the exclusion of underage children and not-cohabiting close relatives from the intervention. This choice may have limited the generalizability of the results, since quite often, BD patients live with their underage children. However, this choice was due to the fact that we aimed to explore the effect of the PFI on adult relatives, and we aim to analyze the effect of BD on underage 


\begin{tabular}{|c|c|c|c|c|c|}
\hline \multicolumn{2}{|c|}{ Coercion } & \multicolumn{2}{|c|}{ Use of alcohol and drugs } & \multicolumn{2}{|c|}{ Seeking for spiritual help } \\
\hline OR $(95 \% \mathrm{Cl})$ & $p$-value & OR (95\% CI) & $p$-value & OR (95\% Cl) & $p$-value \\
\hline$-0.268(-0.46$ to -0.08$)$ & 0.002 & $-0.182(-0.33$ to -0.04$)$ & 0.014 & $-0.002(-0.38$ to 0.38$)$ & 0.994 \\
\hline$-0.220(-0.46$ to 0.02$)$ & 0.071 & $-0.085(-0.27$ to 0.10$)$ & 0.355 & $-0.164(-0.65$ to 0.32$)$ & 0.505 \\
\hline-0.201 ( -0.44 to 0.03$)$ & 0.094 & $0.039(-0.14$ to 0.21$)$ & 0.667 & $-0.498(-0.98$ to -0.02$)$ & 0.042 \\
\hline$-0.173(-10.02$ to 0.67$)$ & 0.685 & $0.466(-0.18$ to 10.11$)$ & 0.154 & $0.110(-10.61$ to 10.83$)$ & 0.899 \\
\hline $0.015(-0.65$ to 0.68$)$ & 0.966 & $0.288(-0.22$ to 0.80$)$ & 0.265 & $0.210(-10.15$ to 10.57$)$ & 0.760 \\
\hline $0.017(-0.72$ to 0.75$)$ & 0.963 & $-0.049(-0.5 \mathrm{I}$ to $0.6 \mathrm{I})$ & 0.864 & -0.104 (-10.60 to 10.39$)$ & 0.891 \\
\hline$-0.144(-0.91$ to 0.62$)$ & 0.710 & $0.298(-0.28$ to 0.88$)$ & 0.313 & $-0.156(-10.70$ to 10.40$)$ & 0.842 \\
\hline $0.003(-0.01$ to 0.01$)$ & 0.654 & $0.002(-0.01$ to 0.01$)$ & 0.702 & $0.018(-0.01$ to 0.04$)$ & 0.119 \\
\hline $0.000(-0.01$ to 0.01$)$ & 0.775 & $-0.00 \mathrm{I}(-0.0 \mathrm{I}$ to $0.0 \mathrm{I})$ & 0.236 & $-0.00 \mathrm{I}(-0.0 \mathrm{I}$ to $0.0 \mathrm{I})$ & 0.718 \\
\hline $0.009(-0.02$ to 0.03$)$ & 0.538 & $0.002(-0.02$ to 0.02$)$ & 0.874 & $0.023(-0.04$ to 0.08$)$ & 0.453 \\
\hline$-0.008(-0.02$ to 0.01$)$ & 0.302 & $0.006(-0.01$ to 0.01$)$ & 0.301 & $-0.013(-0.04$ to 0.02$)$ & 0.419 \\
\hline $0.005(-0.01$ to 0.01$)$ & 0.468 & $-0.010(-0.02$ to 0.00$)$ & 0.070 & $-0.010(-0.04$ to 0.02$)$ & 0.507 \\
\hline$-0.05 \mathrm{I}(-0.22$ to $0.1 \mathrm{I})$ & 0.544 & $-0.056(-0.18$ to 0.07$)$ & $0.38 \mathrm{I}$ & $-0.352(-0.69$ to -0.02$)$ & 0.040 \\
\hline$-0.002(-0.01$ to 0.01$)$ & 0.764 & $-0.002(-0.01$ to 0.01$)$ & 0.657 & $0.016(-0.00$ to 0.04$)$ & 0.119 \\
\hline $0.040(-0.12$ to 0.20$)$ & 0.621 & $-0.065(-0.19$ to 0.06$)$ & 0.298 & $0.135(-0.19$ to 0.46$)$ & 0.413 \\
\hline$-0.008(-0.21$ to 0.19$)$ & 0.934 & $0.047(-0.1$ I to 0.20$)$ & 0.553 & -0.15 I $(-0.56$ to 0.26$)$ & 0.472 \\
\hline $0.009(-0.11$ to 0.13$)$ & 0.883 & 0.053 (-0.04 to 0.15$)$ & 0.269 & $0.078(-0.17$ to 0.33$)$ & 0.540 \\
\hline
\end{tabular}

children in future studies. Moreover, the main aim of this study was to evaluate the efficacy of the PFI according to the Falloon model in coping strategies of those relatives cohabiting with the patient.

\section{Future perspective and conclusion}

PFI is effective in improving problem-oriented coping strategies in family members of patients with BD. This is a very relevant issue since adaptive coping strategies are essential for improving the level of family functioning and, consequently, to improve the long-term course of patients with BD. These findings further support the importance to routinely provide PFI to patients and family members.

Further steps should be focused on the assessment of the level of satisfaction of users and carers with these kinds of interventions. In fact, as recently pointed out in a survey carried out with all the categories of stakeholders involved in mental health, there is the need to include users' perspective in research studies ${ }^{59-62}$ and to promote shared decision making ${ }^{63-69}$ in order to develop a more person-centered approach. ${ }^{70-72}$ Finally, long-term studies can help to evaluate the stability of adaptive coping strategies over time, since these can change as the illness progresses.

\section{Acknowledgment}

The research project has been funded by the Italian Ministry of Health (registration number: 9556/2009).

\section{Author contributions}

AF designed the study and wrote the protocol. AF, VDV, ML, CDR, and CM organized the training and supervision for mental health professionals and coordinated the activities with participating mental health centers. GS, ML, and AT managed the literature searches and analyses. FB, GC, SI, DL, AM, FB, FV, LS, SF, SB, MP, EP, VG, and GB recruited patients and key relatives, carried out the intervention in their center, and coordinated the study in their center. GS, ML, and GC undertook the statistical analyses. ML, GS, VDV, AT, and AF wrote the first draft of the manuscript. All authors contributed toward data analysis, drafting and revising the paper and agree to be accountable for all aspects of the work.

\section{Disclosure}

The authors report no conflicts of interest in this work.

\section{References}

1. Miklowitz DJ, Goldstein MJ, Nuechterlein KH, Snyder KS, Mintz J. Family factors and the course of bipolar affective disorder. Arch Gen Psychiatry. 1988;45:225-231.

2. Miklowitz DJ, Goldstein MJ. Behavioral family treatment for patients with bipolar affective disorder. Behav Modification. 1990;14:457-489.

3. Fadden G, Bebbington P, Kuipers L. The burden of care: the impact of functional psychiatric illness on the patient's family. $\mathrm{Br} J$ Psychiatry. 1987;150:285-292.

4. Miklowitz D, Chung B. Family-focused therapy for bipolar disorder: reflections on 30 years of research. Fam Proc. 2016;55:483-499. 
5. Brown GW, Birley JLT, Wing JK. Influence of family life on the course of schizophrenic disorder. Br J Psychiatry. 1972;121:241-258.

6. Nehra R, Chakrabarti S, Kulhara P, Sharma R. Caregiver-coping in bipolar disorder and schizophrenia-a re-examination. Soc Psychiatry Psychiatr Epidemiol. 2005;40:329-336.

7. McGirr A, Karmani S, Arsappa R, et al. Clinical efficacy and safety of repetitive transcranial magnetic stimulation in acute bipolar depression. World Psychiatry. 2016;15:85-86.

8. Hayes JF, Marston L, Walters K, Geddes JR, King M, Osborn DP. Lithium vs. valproate vs. olanzapine vs. quetiapine as maintenance monotherapy for bipolar disorder: a population-based UK cohort study using electronic health records. World Psychiatry. 2016;15:53-58.

9. Fiorillo A, Sampogna G, Del Gaudio L, Luciano M, Del Vecchio V. Efficacy of supportive family interventions in bipolar disorder: a review of the literature. J Psychopatol. 2013;19:134-142.

10. van der Voort TY, Goossens PJ, van der Bijl JJ. Burden, coping and needs for support of caregivers for patients with a bipolar disorder: a systematic review. J Psychiatr Ment Health Nurs. 2007;14:679-687.

11. Luciano M, Del Vecchio V, Sampogna G, De Rosa C, Fiorillo A. Including family members in psychoeducation for bipolar disorder: is it worth it? Bipolar Disord. 2015;17:458-459.

12. Wasley D, Eden S. Predicting psychological distress of informal carers of individuals with major depression or bipolar disorder. Int $J$ Ment Health Nurs. 2018;27(1):358-367.

13. Goossens PJ, Van Wijngaarden B, Knoppert-van Der Klein EA, Van Achterberg T. Family caregiving in bipolar disorder: caregiver consequences, caregiver coping styles, and caregiver distress. Int $J$ Soc Psychiatry. 2008;54:303-316.

14. Jönsson PD, Wijk H, Danielson E, Skärsäter I. Outcomes of an educational intervention for the family of a person with bipolar disorder: a 2-year follow-up study. J Psychiatr Ment Health Nurs. 2011; 18:333-341.

15. Lazarus RS, Folkman S. Stress, Appraisal and Coping. New York, NY: Springer; 1984.

16. Chakrabarti S, Gill S. Coping and its correlates among caregivers of patients with bipolar disorder: a preliminary study. Bipolar Disord. 2002;4:50-60.

17. Rea MM, Tompson MC, Miklowitz DJ, Goldstein MJ, Hwang S, Mintz J. Family focused treatment vs. individual treatment for bipolar disorder: results of a randomized clinical trial. J Consult Clin Psychol. 2003;71:482-492.

18. Reinares M, Colom F, Rosa AR, et al. The impact of staging bipolar disorder on treatment outcome of family psychoeducation. $J$ Affect Disord. 2010;123:81-86.

19. Reinares M, Colom F, Sánchez-Moreno J, et al. Impact of caregiver group psychoeducation on the course and outcome of bipolar patients in remission: a randomized controlled trial. Bipolar Disord. 2008; 10:511-519.

20. Camardese G, Vasale M, D’Alessandris L, et al. A Mixed program of psychoeducational and psychological rehabilitation for patients with bipolar disorder in a day hospital setting. J Nerv Ment Dis. Epub 2018 Feb 6

21. Dean OM, Gliddon E, Van Rheenen TE, et al. An update on adjunctive treatment options for bipolar disorder. Bipolar Disord. Epub 2018 Jan 25.

22. National Institute for Health and Care Excellence (NICE). Bipolar disorder: assessment and management; 2014. Available from: https:// www.nice.org.uk/guidance/cg185/chapter/1-Recommendations\#carefor-adults-children-and-young-people-across-all-phases-of-bipolardisorder-2. Accessed August 17, 2017.

23. Salcedo S, Gold AK, Sheikh S, et al. Empirically supported psychosocial interventions for bipolar disorder: current state of the research. $J$ Affect Disord. 2016;201:203-214.

24. Bond K, Anderson IM. Psychoeducation for relapse prevention in bipolar disorder: a systematic review of efficacy in randomized controlled trials. Bipolar Disord. 2015;17:349-362.
25. Perlick DA, Miklowitz DJ, Lopez N, et al. Family-focused treatment for caregivers of patients with bipolar disorder. Bipolar Disord. 2010; $12: 627-637$.

26. Eisner LR, Johnson SL. An acceptance-based psychoeducation intervention to reduce expressed emotion in relatives of bipolar patients. Behav Ther. 2008;39:375-385.

27. Falloon IRH. Family Management of Schizophrenia: A Controlled Study of Clinical, Social, Family and Economic Benefits. Baltimore, MD: John Hopkins University Press; 1985.

28. Magliano L, Fadden G, Economou M, et al. Family burden and coping strategies in schizophrenia: 1-year follow-up data from the BIOMED I study. Soc Psychiatry Psychiatr Epidemiol. 2000;35:109-115.

29. Fiorillo A, Del Vecchio V, Luciano M, et al. Efficacy of psychoeducational family intervention for bipolar I disorder: a controlled, multicentric, real-world study. J Affect Disord. 2015;172:291-299.

30. Fiorillo A, Del Vecchio V, Luciano M, et al. Feasibility of a psychoeducational family intervention for people with bipolar I disorder and their relatives: results from an Italian real-world multicentre study. J Affect Disord. 2016;190:657-662.

31. American Psychiatric Association. Diagnostic and Statistical Manual of Mental Disorders. 4th ed. text rev. Washington, DC: American Psychiatric Association; 2000.

32. Magliano L, Fadden G, Economou M, et al. Social and clinical factors influencing the choice of coping strategies in relatives of patients with schizophrenia: results of the BIOMED I study. Soc Psychiatry Psychiatr Epidemiol. 1998;33:413-419.

33. Goldberg JF, Harrow M. Bipolar Disorders. Washington DC: American Psychiatric Press; 1998

34. Jones S, Hayward P, Lam D. Coping with Bipolar Disorder-A Guide to Living with Manic Depression. Oxford: One Word Publications; 2002.

35. Miklowitz DJ. The Bipolar Disorder Survival Guide: What You and Your Family Need to Know. New York, NY: Guildford Press; 2002.

36. Colom F, Vieta E. Manual de Psicoeducacion para el Trastorno Bipolar. [Handbook of psychoeducation for bipolar disorder] Barcelona: Ars medica; 2004. Spanish.

37. McDonald C, Schulze K, Murray MR, Tohen M. Bipolar Disorder. London: Taylor and Francis Group; 2005.

38. Magliano L, Guarneri M, Marasco C, Tosini P, Morosini PL, Maj M. A new questionnaire assessing coping strategies in relatives of patients with schizophrenia: development and factor analysis. Acta Psychiatr Scand. 1996;94:224-228.

39. Fiorillo A, Sampogna G, Luciano M, et al. How do relatives cope with eating disorders? Results from an Italian multicentre study. Int $J$ Eat Disord. 2017;50:587-592.

40. Fiorillo A, Sampogna G, Del Vecchio V, et al. Development and validation of the Family Coping Questionnaire for Eating Disorders. Int $J$ Eat Disord. 2015;48:298-304.

41. LukoffD, Nuechterlein KH, Ventura J. Appendix A: manual for expanded Brief Psychiatric Rating Scale (BPRS). Schizophr Bull. 1986;12: 594-602.

42. World Health Organization. WHO Psychiatric Disability Assessment Schedule. Geneva: WHO; 1988.

43. Magliano L, Fiorillo A, Malangone C, De Rosa C, Maj M; Family Intervention Working Group. Implementing psychoeducational interventions in Italy for patients with schizophrenia and their families. Psychiatr Serv. 2006;57:266-269.

44. Del Vecchio V, Luciano M, Malangone C, et al. Implementing family psychoeducational intervention for bipolar I disorder in 11 Italian Mental Health Centres. J Psychopathol. 2011;17:277-282.

45. Candini V, Buizza C, Ferrari C, et al. Is structured group psychoeducation for bipolar patients effective in ordinary mental health services? A controlled trial in Italy. $J$ Affect Disord. 2013;151:149-155.

46. Pingani L, Fiorillo A, Luciano M, et al. Who cares for it? How to provide psychosocial interventions in the community. Int J Soc Psychiatry. 2013;59:701-705 
47. SPSS Inc. 2009. PASW Statistics for Windows, Version 18.0. Chicago: SPSS Inc.

48. Fiorillo A, Bassi M, de Girolamo G, Catapano F, Romeo F. The impact of a psychoeducational intervention on family members' views about schizophrenia: results from the OASIS Italian multi-centre study. Int J Soc Psychiatry. 2011;57:596-603.

49. Luciano M, Sampogna G, del Vecchio V, et al. The family in Italy: cultural changes and implications for treatment. Int Rev Psychiatry. 2012;24:149-156.

50. Bhugra D, Fiorillo A. Families, functioning and therapies. Int Rev Psychiatry. 2012;24:79-80.

51. Luciano M, Del Vecchio V, Giacco D, De Rosa C, Malangone C, Fiorillo A. A 'family affair'? The impact of family psychoeducational interventions on depression. Expert Rev Neurother. 2012;12:83-91.

52. Ruffolo MC, Nitzberg L, Schoof K. One-session family workshops for bipolar disorder and depression. Psychiatr Serv. 2011;62:323.

53. Vieta E. Improving treatment adherence in bipolar disorder through psychoeducation. J Clin Psychiatry. 2005;66:24-29.

54. Southwick SM, Sippel L, Krystal J, Charney D, Mayes L, Pietrzak R. Why are some individuals more resilient than others: the role of social support. World Psychiatry. 2016;15:77-79.

55. O'Brien MP, Miklowitz DJ, Candan KA, et al. A randomized trial of family focused therapy with populations at clinical high risk for psychosis: effects on interactional behavior. J Consult Clin Psychol. 2014; 82:90-101.

56. Perlick DA, Rosenheck RR, Clarkin JF, Raue P, Sirey J. Impact of family burden and patient symptom status on clinical outcome in bipolar affective disorder. J Nerv Ment Dis. 2001;189:31-37.

57. Del Vecchio V, Luciano M, Malangone C, et al. Implementing family psychoeducational intervention for bipolar I disorder in 11 Italian Mental Health Centres. J Psychopathol. 2011;17:277-282.

58. Reinares M, Sánchez-Moreno J, Fountoulakis KN. Psychosocial interventions in bipolar disorder: what, for whom, and when. $J$ Affect Disord. 2014;156:46-55.
59. Fiorillo A, Luciano M, Del Vecchio V, et al. Priorities for mental health research in Europe: a survey among national stakeholders' associations within the ROAMER project. World Psychiatry. 2013;12:165-170.

60. Forsman AK, Wahlbeck K, Aarø LE, et al. Research priorities for public mental health in Europe: recommendations of the ROAMER project. Eur J Public Health. 2015;25:249-254.

61. Wykes T, Haro JM, Belli SR, et al. Mental health research priorities for Europe. Lancet Psychiatry. 2015;2:1036-1042.

62. Stein DJ. Psychiatric practice: caring for patients, collaborating with partners, or marketing to consumers? World Psychiatry. 2017;16: $156-157$.

63. Coulter A. Shared decision making: everyone wants it, so why isn't it happening? World Psychiatry. 2017;16:117-118.

64. Slade M. Implementing shared decision making in routine mental health care. World Psychiatry. 2017;16:146-153.

65. Tse S. Shared decision making in mental health care settings: perspective, purpose and practice. World Psychiatry. 2017;16:158-160.

66. McCabe R. Involvement in decision making: the devil is in the detail. World Psychiatry. 2017;16:155-156.

67. Scholl I, Barr PJ. Incorporating shared decision making in mental health care requires translating knowledge from implementation science. World Psychiatry. 2017;16:160-161.

68. Freidl M, Pesola F, Konrad J, et al. Effects of clinical decision topic on patients' involvement in and satisfaction with decisions and their subsequent implementation. Psychiatr Serv. 2016;67:658-663.

69. Puschner B, Becker T, Mayer B, et al. Clinical decision making and outcome in the routine care of people with severe mental illness across Europe (CEDAR). Epidemiol Psychiatr Sci. 2016;25:69-79.

70. Uher R. Person-centered measurement-based care for depression. World Psychiatry. 2016;15:238-239.

71. El Chammay R. A policy implementer's perspective. World Psychiatry. 2017;16:43-44.

72. Sunkel C. A service user's perspective. World Psychiatry. 2017;16: 44-45.
Neuropsychiatric Disease and Treatment

\section{Publish your work in this journal}

Neuropsychiatric Disease and Treatment is an international, peerreviewed journal of clinical therapeutics and pharmacology focusing on concise rapid reporting of clinical or pre-clinical studies on a range of neuropsychiatric and neurological disorders. This journal is indexed on PubMed Central, the 'PsycINFO' database and CAS,

\section{Dovepress}

and is the official journal of The International Neuropsychiatric Association (INA). The manuscript management system is completely online and includes a very quick and fair peer-review system, which is all easy to use. Visit http://www.dovepress.com/testimonials.php to read real quotes from published authors. 